\title{
Role Responsibilities of Full-Time Faculty in a Pre-licensure Nursing Program
}

\section{Joan R. Dugas*}

Assistant Clinical Professor, Nursing, University of Rhode Island, USA

\begin{abstract}
The purpose of this article it to describe the roles and responsibilities of a full-time faculty member in a prelicensure baccalaureate nursing program. The article will discuss the expectations of the faculty role to encourage RNs to pursue this role. The interview process, teaching, research and service responsibilities, and evaluations by students and peers will be addressed.
\end{abstract}

\section{Keywords: Nursing faculty; Role}

\section{Introduction}

The nursing literature reveals an expected shortage of faculty and nurses. In September 2011, the AACN reported a national nursing faculty shortage of $7.7 \%$ [1]. U. S. nursing schools turned away 67,563 qualified applicants from baccalaureate and graduate nursing programs in 2010 due to insufficient number of faculty. This survey of 605 nursing schools (baccalaureate and/or graduate programs) reported a need to create an additional 104 faculty positions to accommodate student demand. The purpose of this article is two-fold: summarize the major role responsibilities of full-time faculty in a pre-licensure nursing program and encourage RNs to pursue this career path. The opportunity to teach one-on-one with nursing students is very rewarding. The role is very flexible and inspires autonomous, self-directed individuals. This rewarding career will enable one to conduct research and publish articles. The article's aim is to encourage RNs to teach nursing by discussing the interview process, contractual role responsibilities, and the peer review process one will experience in this role.

\section{The Interview Process}

The interview process for a full-time faculty appointment is performed before the Search Committee. The Search committee is comprised of elected members of the existing faculty and the Dean of the College or School of Nursing. The length of the interview process will be between 1 to 2 hours. During the interview the candidate will discuss their nursing experience, perform a teaching presentation, and answer questions regarding their area of expertise. The teaching presentation should be in their area of expertise which would allow for the candidate to do an in-depth presentation and confidently answer questions. Questions will be asked regarding the candidate's individual area of expertise, research interest, and goals. To prepare for this interview one should be familiar with the mission and the vision of the institution, practice the teaching presentation, and have a list of questions to ask the Search committee.

\section{Contractual Agreement}

Once selected, you will sign a contractual agreement which will outline specific role responsibilities. It will describe the rank of appointment, length of term, credit hours of teaching (this varies per institution), and responsibilities with regard to research and service. The contract will contain specific information regarding the following three areas: teaching, research, and service.

The teaching assignment will be based on your area of expertise and experience. The assignment may include teaching in the classroom, skills laboratory, simulation, or the clinical setting. The selected candidate may be assigned a team-teaching or independent teaching assignment. It is very helpful in the beginning of one's teaching career to be assigned a mentor. A mentor can assist with questions regarding grading, accessing rosters, classroom equipment, etc.

\section{Research}

The role responsibility with regard to research will be specific to your contract and institution. It is expected that all faculty will advance nursing knowledge through publications and presentations at professional meetings. The publications can be in books or journals. Your individual area of interest and expertise will guide the content of your publications.

\section{Service}

As part of the contractual agreement, attendance at meetings and participation on committees at the department, college, and university levels will be expected. The administrative team will determine the committee assignment. Committee work is a very important component of your role responsibilities. Decisions made at the committee level are discussed at the faculty meetings. Decisions brought forth to the entire undergraduate faculty meetings from individual committees change educational practices in the nursing program. Program Evaluation, Curriculum, Faculty Affairs, Scholastic Standing, and Research are committees often seen in nursing programs. As part of the service component of your contract, you may represent the college at the university level as well as the community at large. The community service component can include membership on a Board, elected positions of nursing associations, and volunteer work.

\section{Peer Review}

Peer review is "a process by which something proposed is evaluated by a group of experts in the appropriate field" [2]. Every faculty member is peer-reviewed. The timing of your peer review is based on your rank of appointment. Your peer review will be conducted by existing faculty members who are elected to serve on the Peer Review Committee. The Peer Review committee will review your submitted documents, sometimes called a portfolio, and make recommendations.

*Corresponding author: Joan R Dugas, Assistant Clinical Professor, Nursing University of Rhode Island, USA, E-mail: jrdugas@mail.uri.edu

Received September 10, 2012; Accepted October 25, 2012; Published October 30, 2012

Citation: Dugas JR (2012) Role Responsibilities of Full-Time Faculty in a Prelicensure Nursing Program. J Nurs Care S4:001. doi:10.4172/2167-1168.S4-001

Copyright: (c) 2012 Dugas JR. This is an open-access article distributed under the terms of the Creative Commons Attribution License, which permits unrestricted use, distribution, and reproduction in any medium, provided the original author and source are credited. 
The documents submitted are to support your retention or promotion in rank. Such items included are your individual student evaluations of teacher (SET) scores, classes taught and number of students, publications, participation on committees, community service, and continuing education. It is very helpful to keep a list of your goals and accomplishments each semester. Your peer review period may occur every 2 to 3 years. Documentation of your goals and accomplishments throughout the academic year will assist you when preparing your peer review material. During the peer review process your colleagues are encouraged to write about your individual achievements with regard to teaching, research, and service. You will receive a formal letter from the Dean and members of the Search committee which will include a summary of your peer review along with the recommendations.

\section{Conclusion}

It is important for RNs to consider a career as a full-time faculty member in a pre-licensure nursing program. Working one-on-one with nursing students is very rewarding. This position will allow for flexibility and autonomy in a collegial work environment. The role responsibilities outlined above provide a clear picture of the opportunity to advance nursing knowledge through teaching, service and research.

\section{References}

1. American Association of Colleges of Nursing (AACN) (2012) Nursing Faculty Shortage.

2. Definition of Peer Review 